\title{
Identification of a Panel of MiRNAs as Positive Regulators of Insulin Release in Pancreatic B-Cells
}

\author{
Hongmei Lang Yang Xiang Ning Lin Zhihua Ai Zhiqing You \\ Jie Xiao Dan Liu Yongjian Yang \\ Department of Endocrinology, Department of Cardiovascular and Department of Neurology, Chengdu \\ Military General Hospital, Chengdu, China
}

\section{Key Words}

Insulin release $\cdot$ Mitochondrial UCP2 $\bullet$ MicroRNA $•$ Beta cells

\begin{abstract}
Background/Aims: MicroRNAs (miRNAs) are a novel class of small RNAs that participate in a variety of biological processes. Although miRNAs have been linked to insulin synthesis and glucose homeostasis, their role in the targeting of mitochondrial uncoupling protein 2 (UCP2), a negative modulator of insulin secretion, remains unclear. Methods: miRNA levels were determined by real-time quantitative PCR analysis using TaqMan probes, and insulin secretion from isolated islets was quantified by ELISA. Effects of miRNAs on UCP2 expression were checked with a luciferase assay and western blotting analysis. Results: An overall change in a set of miRNAs was discovered, with miR-15a, miR-424, miR-497, and miR-185 coinciding with insulin levels in islets maintained under high-glucose conditions. Moreover, experiments in MIN6 cells illustrated that miR-15a, miR-424, miR-497, and miR-185 positively regulated insulin biosynthesis by co-inhibiting UCP2 expression. Furthermore, the four miRNAs were found to post-transcriptionally repress UCP2 expression by directly targeting the 3'UTR of UCP2 mRNA. Conclusions: Thus, our results shed further light on the regulatory network in $\beta$-cells consisting of miRNAs, UCP2, and insulin and provide novel therapeutic targets for diabetes.

\section{Introduction}

Diabetes is a complex, multisystem disease and the most common metabolic disorder [1, 2]. Type 2 diabetes is characterized by insulin resistance, with or without abnormal insulin secretion, leading to insufficient insulin production and subsequent diabetes mellitus $[3,4]$. Pancreatic $\beta$-cells as well as their endocrine product insulin play central roles in glucose

H. Lang and Y. Xiang contributed equally to this work.

Yongjian Yang

KARGER
Dept. of Endocrinology, Dept. of Cardiovascular and Dept. of Neurology, Chengdu Milit. Gen. Hosp. Chengdu, Sichuan 610083 (China)

E-Mail yangyongjian38@sina.com 
homeostasis and diabetes pathogenesis, and glucose is the main stimulator of insulin biosynthesis and secretion $[5,6]$. However, the direct molecular mechanism of glucosestimulated insulin secretion (GSIS) is still unclear.

MicroRNAs (miRNAs) are a family of small noncoding RNAs [7] that plays important roles in various biological pathways by post-transcriptionally inhibiting the expression of genes via base pairing to the target mRNAs $[8,9]$. miRNAs also play fundamental roles in a wide variety of biological processes, including developmental timing, apoptosis, proliferation, differentiation, the immune response, and energy metabolism $[8,9]$.

Mitochondrial uncoupling protein 2 (UCP2) belongs to the superfamily of mitochondrial anion carriers that is located in the inner membrane of mitochondria [10]. UCP2 is believed to uncouple oxygen consumption during respiration and reduce ATP production by mediating proton leaks [11]. UCP2 is a negative regulator of insulin secretion, with islets of UCP2 knockout mice generating much more insulin [12] and UCP2 overexpression in isolated rat islets inhibiting GSIS [13].

Increasing evidence shows that miRNAs participate in the insulin secretion process $[14,15]$. miR-133a and miR-375 enhance insulin secretion by repressing polypyrimidine tract-binding protein and myotrophin protein expression, respectively [16-18]. However, the interaction between miRNAs and insulin release remains unclear.

miR-15a, miR-424, miR-497, and miR-185 are implicated in human cancer, metabolic processes, the immune escape of tumor cells, and many other disease processes $[19,20]$. However, few studies have focused on their role in $\beta$-cell function. In this study, miR-15a, miR-424, miR-497, and miR-185 were identified as positive regulators of GSIS. These miRNAs were first identified because they showed a clear variation in mouse islets exposed to high glucose. MIN6 cells overexpressing the four miRNAs showed a marked increase in insulin secretion, whereas knockdown of the four miRNAs inhibited insulin secretion. Subsequently, all of the miRNAs were found to directly target UCP2 mRNA and to regulate insulin secretion by inhibiting UCP2 expression. The miRNA levels in UCP2-deficient mouse islets were in accordance with those in wild-type mouse islets, showing that the four miRNAs were upstream regulators of insulin secretion, with UCP2 in the downstream position. Therefore, this study helps to explain this novel pathway, comprising glucose, miRNA, and insulin, in $\beta$-cell function.

\section{Materials and Methods}

\section{Animals}

C57/BL6 mice (6-8 weeks) were purchased from the Model Animal Research Center of Nanjing University. All animal care and handling procedures were performed in accordance with the National Institute of Health's Guide for the Care and Use of Laboratory Animals and approved by the Institutional Review Board of Chengdu Military General Hospital, Chengdu, China.

\section{Isolation of islets from mouse pancreas}

Islet isolation was performed as previously described with slight modifications [21]. Mice were anesthetized by intraperitoneal injection of sodium pentobarbital. Pancreatic islets were then isolated by pancreatic duct injection of $500 \mathrm{U} / \mathrm{ml}$ of collagenase solution followed by digestion at $37^{\circ} \mathrm{C}$ for 28 min with mild shaking. Islets were washed several times with D-Hanks $(136 \mathrm{mM} \mathrm{NaCl}, 0.53 \mathrm{mM} \mathrm{KCl}, 4.2 \mathrm{mM} \mathrm{NaHCO}$, $0.44 \mathrm{mM} \mathrm{KH}_{2} \mathrm{PO}_{4}, 0.385 \mathrm{mM} \mathrm{Na}_{2} \mathrm{HPO}_{4} .12 \mathrm{H}_{2} \mathrm{O}$ ), separated from acinar cells using a discontinuous Ficoll 400 gradient, viewed under a dissecting microscope, and hand-selected. Finally, the islets were collected and transferred into RPMI1640 medium containing 10\% fetal bovine serum.

Islets were cultured at $37^{\circ} \mathrm{C}$ in a humidified atmosphere containing $5 \% \mathrm{CO}_{2} / 95 \%$ air for $12 \mathrm{~h}$ (primary culture) to remove exocrine and other tissues. Subsequently, islets were transferred into Dulbecco's modified Eagle's medium (DMEM) containing 5.6 or $28 \mathrm{mM}$ glucose for insulin secretion studies. 


\section{Cellular Physiology Cell Physiol Biochem 2018;48:185-193 \begin{tabular}{l|l} 
and Biochemistry Published 10.1159/000491717 & $\begin{array}{l}\text { C) } 2018 \text { The Author(s). Published by S. Karger AG, Basel } \\
\text { www.karger.com/cpb }\end{array}$ \\
\hline
\end{tabular}}

Lang et al.: Four MiRNAs Co-Regulate Insulin Secretion

\section{RNA isolation and PCR assays}

Total RNA was extracted from the cultured cells and mouse islets using TRIzol Reagent (Invitrogen) according to the manufacturer's instructions. Assays to quantify mature miRNAs were conducted as described previously, and real-time PCR was performed using a TaqMan PCR kit. In this study, miRNA expression in cells and islets was normalized to U6 snRNA. The relative amount of each gene to the internal control was calculated by using the $2^{-\Delta \mathrm{CT}}$ equation, in which $\Delta \mathrm{CT}=\mathrm{C}_{\mathrm{Tgene}}-\mathrm{C}_{\mathrm{T} \mathrm{U}}{ }^{\circ}$

To determine the mRNA expression of UCP2 and insulin, the following primers were designed: UCP2 (sense): 5'-TCAGAATGGTGCCCATCACA-3', UCP2 (antisense): 5'-CCGGTTACAGATCCAAGGAGAA-3'; insulin (sense): 5'-CACTTCCTACCCCTGCTGG-3', insulin (antisense): 5'-ACCACAAAGATGCTGTTTGACA-3'; GAPDH (sense): 5'-AGAAGGCTGGGGCTCATTTG-3', GAPDH (antisense): 5'-AGGGGCCATCCACAGTCTTC-3'. mRNA expression was evaluated using agarose polyacrylamide gel electrophoresis with GAPDH as the internal control.

\section{Determination of insulin secretion}

Secreted insulin was measured using the Rat/Mouse Insulin ELISA Kit (EMD Millipore; catalog number, EZRMI-13K). Insulin secretion was assessed as described; batches of 10 islets each were incubated in DMEM. For the measurement of insulin secretion from islets exposed to long-term $(72 \mathrm{~h})$ high glucose, the medium was removed at the 71st hour, fresh DMEM with the desired amount of glucose was added, and medium was collected on the 72nd hour for ELISA analysis.

To determine the insulin secretion of MIN6 cells, medium was removed from the wells and the cells were washed twice with PBS. Then, FBS-free DMEM with $5.6 \mathrm{mM}$ glucose was added to each well and the cells were cultured for another $1 \mathrm{~h}$. Mature insulin from MIN6 cells was normalized to total insulin.

\section{Cell culture}

MIN6 cells were routinely maintained in RPMI 1640 supplemented with $20 \%$ heat-inactivated fetal bovine serum (FBS), $1 \%$ glutamine, $1 \% \beta$-mercaptoethanol, and $10 \mathrm{mM}$ HEPES. Cells were cultured at $37^{\circ} \mathrm{C}$ with $5 \% \mathrm{CO}_{2}$.

MIN6 cells were routinely maintained in DMEM supplemented with $10 \%$ heat-inactivated fetal calf serum and cultured at $37^{\circ} \mathrm{C}$ with $5 \% \mathrm{CO}_{2}$. MIN6 cells were treated with $5 \mathrm{mM}$ glucose in RPMI for $18 \mathrm{~h}$ and then with $2.5 \mathrm{mM}$ glucose in KRB buffer ( $135 \mathrm{mM} \mathrm{NaCl}, 3.6 \mathrm{mM} \mathrm{KCl}, 10 \mathrm{mM}$ HEPES [pH 7.4], $5 \mathrm{mM} \mathrm{NaHCO}{ }_{3}$, $0.5 \mathrm{mM} \mathrm{NaH}_{3} \mathrm{PO}_{4}, 0.5 \mathrm{mM} \mathrm{MgCl}_{2}, 1.5 \mathrm{mM} \mathrm{CaCl}_{2}$ ) for $1 \mathrm{~h}$. The cells were stimulated with $\mathrm{KRB}$ buffer containing 5.6 or $33 \mathrm{mM}$ glucose for $1 \mathrm{~h}$ or 3 days. Lysates from these cells were subjected to sodium dodecyl sulfate polyacrylamide gel electrophoresis. Insulin was measured by immunoblot analysis using guinea pig antimouse insulin antibody (ab7842, Abcam).

\section{Cell transfections}

MIN6 cells were seeded on 6-well plates and transfected by using Lipofectamine 2000 (Invitrogen) according to the manufacturer's instructions. For each well, equal doses (100 nM) of miRNA mimics, inhibitors, or scrambled negative control RNA were used. For the co-transfection of miRNAs, the total concentration was $100 \mathrm{nM}$, with equal amounts of each miRNA. Cells were harvested $24 \mathrm{~h}$ after transfection for real-time PCR analysis and western blotting.

\section{Plasmid construction and luciferase assay}

Part of the 3'-untranslated region (UTR) segment (1-50) of UCP2 was synthesized and inserted into a p-MIR-report plasmid (Ambion). Then, a plasmid with a mutated 3'UTR of UCP2 was also built with the same method. For luciferase reporter assays, $2 \mu \mathrm{g}$ of firefly luciferase reporter plasmid, $2 \mu \mathrm{g}$ of $\beta$-galactosidase expression vector (Ambion), and equal amounts $(200 \mathrm{pmol})$ of mimics, inhibitors, or scrambled negative control RNA were transfected into cells in 6-well plates. The $\beta$-galactosidase vector was used as a transfection control. At $24 \mathrm{~h}$ after transfection, cells were assayed using luciferase assay kits (Promega).

\section{Western blot analysis}

UCP2 expression was assessed by western blot analysis and sample levels were normalized to GAPDH. Protein extraction was blocked with 5\% fat-free dried milk in PBS at room temperature for $1 \mathrm{~h}$ and incubated at $4^{\circ} \mathrm{C}$ overnight with anti-UCP2 (1:1000, Santa Cruz) and anti-GAPDH (1:1000, Santa Cruz) antibodies. 
Statistical analysis

All data are representative of at least three independent experiments. Data are expressed as the mean \pm standard deviation of three separate experiments. A p value less than 0.05 using the Student's $t$-test was considered significant. * indicates $\mathrm{p}<0.05,{ }^{* *}$ indicates $\mathrm{p}<0.01$, and ${ }^{* * *}$ indicates $\mathrm{p}<0.001$.

\section{Results}

Effects of high glucose on the expression of $\beta$-cell UCP2

Mitochondrial UCP2 is regarded as a negative modulator of insulin secretion [22]. Accumulating evidence indicates that the $\beta$-cell levels of UCP 2 may be upregulated by glucolipotoxicity, which decreases insulin secretion [23]. In this study, the effects were assessed of both short- and long-term high glucose on UCP2 expression in islets. The UCP2 concentration was lower in islets treated with short-term high glucose than in islets cultured in normal glucose medium $(5.6 \mathrm{mM})$, whereas UCP2 was significantly increased in islets cultured under long-term high-glucose conditions (Fig. 1A and 1B). The observations confirmed that UCP2 is an important regulator during glucose-induced insulin secretion and that UCP2 negatively regulates insulin secretion. However, UCP2 mRNA showed little change under both conditions (Fig. 1C). These findings suggest that glucose regulates UCP2 expression at the post-transcriptional level.

\section{Short- and long-term effects of high glucose on UCP2-related miRNAs}

Glucose is regarded as the main stimulator of insulin biosynthesis and its rapid secretion from $\beta$-cells [5]. Glucose-induced insulin expression in islets may be partly regulated by autocrine factors, including miRNAs. In the present study, four significant miRNAs were identified for their potential interaction with UCP2 mRNA via bioinformatics methods (Fig. 1D).

The levels of miR-15a, miR-424, miR-497, and miR-185 were increased in islets treated with high glucose for $1 \mathrm{~h}$ (Fig. 1E), whereas they showed a relative decrease after 72 -h stimulation (Fig. 1F).

These data suggested that upregulation of the four miRNAs may positively regulate insulin secretion from islets, whereas their downregulation may impair insulin secretion.

Fig. 1. The expression patterns of UCP2 and miRNAs in glucose-treated islets. (A, B) Effects of short-term and long-term high glucose on UCP2 expression in islets ( $n=3)$. (C) Quantification of UCP2 mRNA in islets exposed to high glucose (n=3). (D) Graphical description of miRNA binding sites in UCP2 mRNA. (E) Levels of UCP2-related miRNAs in islets treated with short-term high glucose (n=3). (F) Levels of UCP2related miRNAs in islets treated with long-term high glucose $(n=3) . * * p<0.01$.

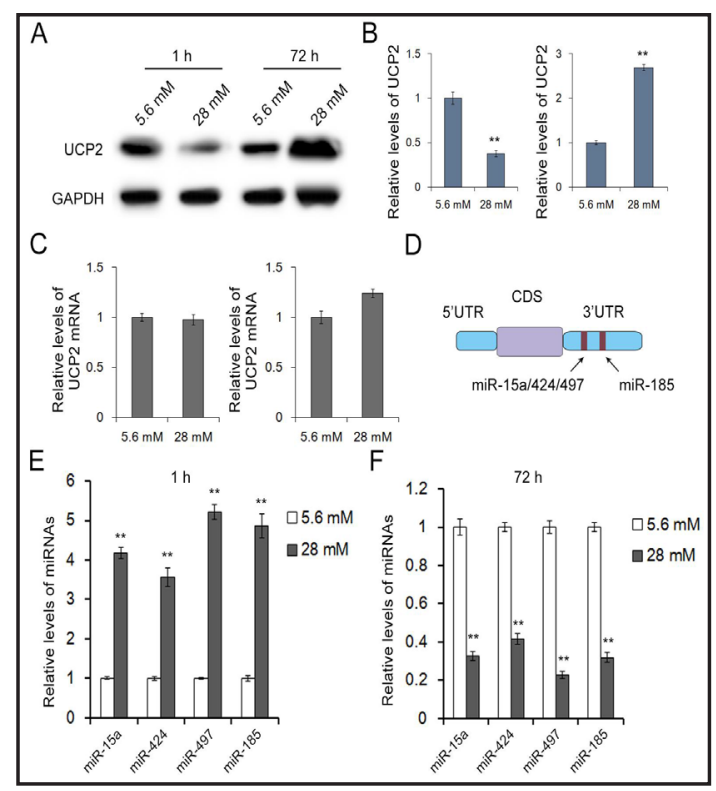


Fig. 2. miRNA levels and insulin secretion in UCP2ablated and ob/ob mouse islets exposed to glucose. Expression of miR-15a, $-424,-497$, and -185 in UCP2-ablated mouse islets exposed to glucose for $1 \mathrm{~h}(\mathrm{~A})$ and $72 \mathrm{~h}(\mathrm{~B})$. (C-D) Effects of $28 \mathrm{mM}(\mathrm{C})$ and $5.6 \mathrm{mM}$ (D) glucose on insulin secretion in UCP2deficient mouse islets. (E, F) Relative levels of miR15a, $-424,-497$, and -185 in ob/ob mouse islets treated with glucose for $1 \mathrm{~h}(\mathrm{E})$ and $72 \mathrm{~h}(\mathrm{~F})$. (G) Characterization of UCP2 expression in glucosetreated islets isolated from ob/ob mice. ${ }^{*} \mathrm{p}<0.05$, ${ }^{* *} \mathrm{p}<0.01$.

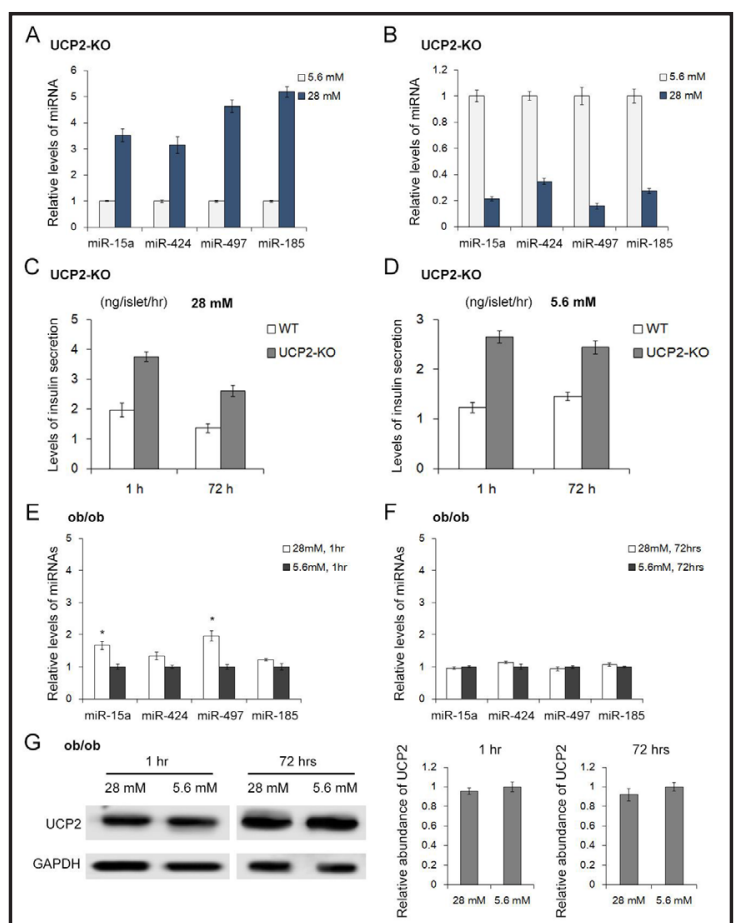

miRNA expression levels in UCP2 knockout and ob/ob mouse islets are consistent with those in wild-type mouse islets

To determine whether the four miRNAs were upstream regulators in the GSIS pathway, we next checked the effects of high glucose on miRNA expression in UCP2 knockout mouse islets. As shown in Fig. 2A, short-term exposure to high glucose significantly increased the expression levels of miR-15a, miR-424, miR-497, and miR-185 in UCP2-deficient mouse islets. In contrast, the four miRNAs showed a relative decrease under the effects of long-term high glucose (Fig. 2B). Insulin secretion was clearly higher from UCP2 knockout islets than from wild-type islets (Fig. 2C). These results were in accordance with those from wild-type mouse islets.

Ob/ob mice are a well-known diabetes model. Here, we also checked the expression pattern of the four miRNAs and UCP2 in the islets of ob/ob mice. miR-15a, -424, -497, and -185 showed little change with short- and long-term glucose (Fig. 2E and 2F). Islet UCP2 is upregulated in diabetes; our results showed that 1-h exposure to high-glucose could not suppress UCP2 expression in the islets of ob/ob mice (Fig. 2G).

These results illustrated that high glucose affected miRNA expression in $\beta$-cells without the intermediary regulation of UCP2.

miR-15a, miR-424, miR-497, and miR-185 directly target the 3'UTR of UCP2

To determine the target genes of miR-424, miR-497, and miR-185 in $\beta$-cell function, we first obtained the candidates of the four miRNAs via bioinformatics methods and found that they might all regulate UCP2 expression (Fig. 3A). In addition, part of the 3'UTR of UCP2 containing the predicted target regions was fused into a downstream position of the firefly luciferase plasmid. The plasmid was introduced into 293T HEK cells in conjunction with a transfection control plasmid (beta-gal). As expected, overexpression of the four miRNAs significantly decreased luciferase reporter activity compared with scramble ncRNA (Fig. 3B). However, the reporter activity repression was almost fully rescued when the target regions were mutated (Fig. 3B).

miR-15a, -424, -497, and -185 promote insulin section in MIN6 cells by suppressing UCP2

To study the physiological role of the four miRNAs in $\beta$-cells, MIN6 cells were transfected with mimics and inhibitors of miR-15a, miR-424, miR-497, and miR-185. Real- 
Fig. 3. miR-15a, $-424,-497$, and -185 directly cotarget the 3'UTR of UCP2. (A) Schematic description of the targeting sites of the four miRNAs in the 3'UTR of UCP2. (B) Firefly luciferase activity of the wild-type and mutated 3'UTR of UCP2 in 293T HEK cells. ${ }^{* *} \mathrm{p}<0.01$.

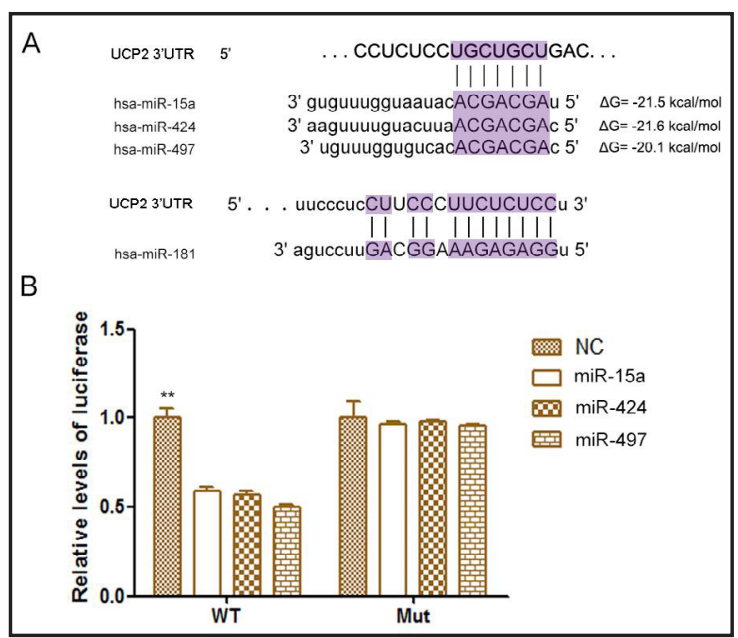

Fig. 4. miR-15a, $-424,-497$, and -185 promote insulin secretion while inhibiting UCP2 expression in MIN6 cells. MIN6 cells were transfected with mimics and inhibitors of the four miRNAs. The relative levels of miR-15a, $-424,-497$, and -214 in MIN6 cells transfected with mimics (A) and inhibitors (B) $(n=3)$. The effects of overexpression (C) and knockdown (D) of miR-15a, -424, -497, and -185 on UCP2 proteins levels in MIN6 cells $(n=3)$. (E, F) Quantification of UCP2 in C and D, respectively $(n=3)$. Overexpression of miR-15a, $-424,-497$, and -185 increased insulin secretion (G), whereas their knockdown slightly decreased insulin secretion $(\mathrm{H})$ in MIN6 cells $(\mathrm{n}=3)$. ${ }^{* *} \mathrm{p}<0.01$, $* * * \mathrm{p}<0.001$.

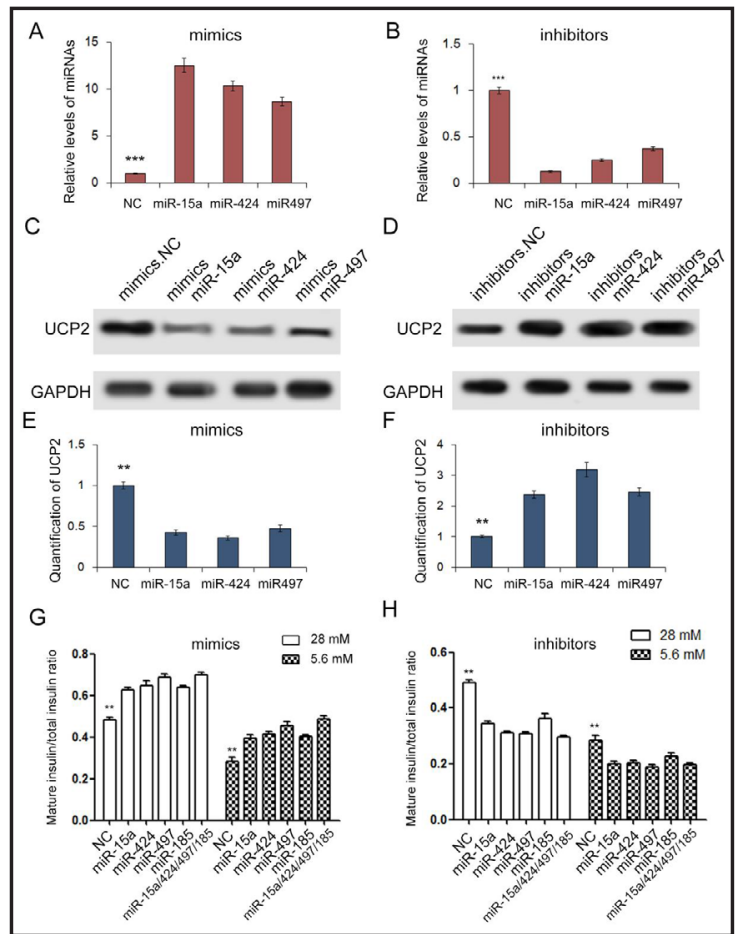

time quantitative PCR analysis showed that the four miRNAs were respectively increased and decreased significantly by the appropriate mimics and inhibitors (Fig. 4A and 4B). Overexpressed miR-15a, -424, -497, and -185 down-regulated UCP2 levels (Fig. 4C and 4E), whereas transfection of miRNA inhibitors slightly promoted UCP2 expression (Fig. 4D and 4F). The overexpression of miR-15a, miR-424, miR-497, and miR-185 in MIN6 cells led to increased secretion of insulin (Fig. 4G), whereas MIN6 cells with knockdown of the miRNAs showed a clear decrease in insulin secretion (Fig. 4H). Thus, the four miRNAs positively regulate insulin secretion in MIN6 cells.

\section{Silencing of UCP2 promotes insulin secretion}

To further confirm that UCP2 plays a key role in $\beta$-cell function, we used siRNA to knockdown UCP2 in MIN6 cells. Both mRNA and protein were suppressed by the siRNAs (Fig. 5A-5C). As expected, silencing of UCP2 significantly promoted insulin secretion from MIN6 cells (Fig. 5D). In addition, co-transfection of UCP2 siRNA and miR-15a, -424, -497, and -185 did not lead to further changes compared with the UCP2 siRNA group. 
Fig. 5. Effects of UCP2 siRNA on insulin secretion. MIN6 cells were transfected with UCP2 siRNA, and UCP2 expression and insulin secretion were analyzed. UCP2 protein (A, B) and UCP2 mRNA (C) were significantly downregulated under the effects of UCP2 siRNA. Insulin secretion was enhanced (D) with knockdown of UCP2 in MIN6 cells. ${ }^{* *} \mathrm{p}<0.01$.

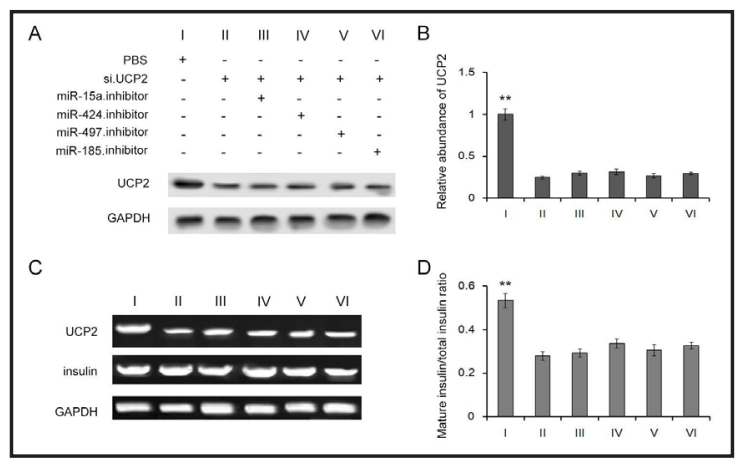

These findings clearly demonstrate that miR-15a, miR-424, miR-497, and miR-185 directly repress UCP 2 translation in $\beta$-cells through a post-transcriptional mechanism.

\section{Discussion}

The number of identified miRNAs is continuously increasing, but the information regarding their roles in biological processes and cellular function remains limited. Thus far, several miRNAs have been reported to participate in diabetes development, as well as insulin biosynthesis and secretion [15, 24]. However, because few studies have focused on the miRNA-insulin network, it is still difficult to obtain a comprehensive understanding of the potential mechanism. One of the main challenges to understanding the function of miRNAs is to identify their genuine target genes in $\beta$-cells.

Glucose is an important regular of $\beta$-cell function, with short- and long-term highglucose conditions having different effects on insulin secretion $[25,26]$. Islet $\beta$-cells are able to immediately improve insulin secretion in response to high-glucose stimulation, whereas prolonged high glucose, known as glucolipotoxicity, decreases insulin secretion [25-27]. Although a few studies have focused on this phenomenon, the differences between the mechanisms of short- and long-term high glucose remain unclear. One explanation for the insulin decrease induced by prolonged high glucose is that high glucose itself may contribute to $\beta$-cell dysfunction $[27,28]$. On the other hand, we believe that miRNAs play a key role in this process, considering that several miRNAs showed clear variations in mouse islets exposed to high glucose.

Although UCP2 shares high identity with UCP1, and both of them have uncoupling activity, the primary physiological role of UCP2 remains unknown [10]. The mild uncoupling effects of UCP2 are likely to play a signaling role [11], and miRNAs may participate in the UCP2-mediated biological process [29]. Studies based on UCP2 knockout mice have shown that UCP2 inhibits insulin secretion [12] and accumulating evidence indicates that $\beta$-cell UCP2 is upregulated by prolonged glucolipotoxic conditions [13, 22]. Our results are in concordance with those of the previous studies.

Because miR-15a has been reported to inhibit $\beta$-cell UCP2 expression [30], it was used as a positive control. miR-424, miR-497, miR-185, and miR-15a showed clear variations in islets. In addition, the subsequent western blotting analysis of UCP2 in miRNA-overexpressed MIN6 cells confirmed these findings. The insulin determination by ELISA was also consistent with the prediction.

Here, high glucose was shown to have effects on the expression of miRNAs and UCP2 in $\beta$-cells, thus regulating insulin secretion. However, the upstream and downstream regulators have not yet been determined. High glucose was found to lead to the same variation in the four miRNAs in both wild-type and UCP2-deficient islets, indicating that these miRNAs were upstream regulators in the GSIS pathway.

In summary, miR-15a, miR-424, miR-497, and miR-185 were revealed to target $\beta$-cell UCP2 and regulate insulin secretion. Precise understanding of the role of miRNAs and their 
underlying mechanism in glucose-induced insulin secretion may open a new method of treatment for diseases such as diabetes.

\section{Acknowledgements}

This study was funded by the Youth Innovation Talent Fund (41732C11C). The funder had no role in study design; collection, analysis, or interpretation of data; in the writing of the report; or in the decision to submit this article for publication.

Hongmei Lang and Yang Xiang performed most of the experiments, analyzed data, and wrote the manuscript. Ning Lin, Zhihua Ai, Zhiqing You, Jie Xiao, and Dan Liu performed some experiments and edited the manuscript. Yongjian Yang designed the experiments and edited the manuscript. Yongjian Yang is the guarantor of this work, has full access to all of the data in the study, and takes responsibility for the integrity of the data and the accuracy of the data analysis.

\section{Disclosure Statement}

The authors declare that there is no conflict of interests regarding this article.

\section{References}

1 Adams KF, Schatzkin A, Harris TB, Kipnis V, Mouw T, Ballard-Barbash R, Hollenbeck A, Leitzmann MF: Overweight, obesity, and mortality in a large prospective cohort of persons 50 to 71 years old. N Engl J Med 2006;355:763-778.

-2 Shaw JE, Sicree RA, Zimmet PZ: Global estimates of the prevalence of diabetes for 2010 and 2030 Diabetes Res Clin Pract 2010;87:4-14.

-3 Kahn SE: Clinical review 135: The importance of beta-cell failure in the development and progression of type 2 diabetes. J Clin Endocrinol Metab 2001;86:4047-4058.

4 Cnop M, Welsh N, Jonas JC, Jorns A, Lenzen S, Eizirik DL: Mechanisms of pancreatic beta-cell death in type 1 and type 2 diabetes: many differences, few similarities. Diabetes 2005;54 Suppl 2:S97-107.

5 Melloul D, Ben-Neriah Y, Cerasi E: Glucose modulates the binding of an islet-specific factor to a conserved sequence within the rat I and the human insulin promoters. Proc Natl Acad Sci U S A 1993;90:3865-3869.

6 Tillmar L, Carlsson C, Welsh N: Control of insulin mRNA stability in rat pancreatic islets. Regulatory role of a 3'-untranslated region pyrimidine-rich sequence. J Biol Chem 2002;277:1099-1106.

7 Lee RC, Feinbaum RL, Ambros V: The C. elegans heterochronic gene lin-4 encodes small RNAs with antisense complementarity to lin-14. Cell 1993;75:843-854.

8 Ambros V: The functions of animal microRNAs. Nature 2004;431:350-355.

9 Bartel DP: MicroRNAs: genomics, biogenesis, mechanism, and function. Cell 2004;116:281-297.

10 Krauss S, Zhang CY, Lowell BB: The mitochondrial uncoupling-protein homologues. Nat Rev Mol Cell Biol 2005;6:248-261.

-11 Brand MD, Esteves TC: Physiological functions of the mitochondrial uncoupling proteins UCP2 and UCP3 Cell Metab 2005;2:85-93.

-12 Zhang CY, Baffy G, Perret P, Krauss S, Peroni O, Grujic D, Hagen T, Vidal-Puig AJ, Boss O, Kim YB, Zheng XX, Wheeler MB, Shulman GI, Chan CB, Lowell BB: Uncoupling protein-2 negatively regulates insulin secretion and is a major link between obesity, beta cell dysfunction, and type 2 diabetes. Cell 2001;105:745-755.

13 Chan CB, MacDonald PE, Saleh MC, Johns DC, Marban E, Wheeler MB: Overexpression of uncoupling protein 2 inhibits glucose-stimulated insulin secretion from rat islets. Diabetes 1999;48:1482-1486.

14 Tang X, Tang G, Ozcan S: Role of microRNAs in diabetes. Biochim Biophys Acta 2008;1779:697-701.

15 Shantikumar S, Caporali A, Emanueli C: Role of microRNAs in diabetes and its cardiovascular complications. Cardiovasc Res 2012;93:583-593. 


\section{Cellular Physiology Cell Physiol Biochem 2018;48:185-193 \begin{tabular}{l|l} 
DOI: 10.1159/000491717 & O 2018 The Author(s). Published by S. Karger AG, Basel \\
www.karger.com/cpb
\end{tabular}}

Lang et al.: Four MiRNAs Co-Regulate Insulin Secretion

16 Poy MN, Eliasson L, Krutzfeldt J, Kuwajima S, Ma X, Macdonald PE, Pfeffer S, Tuschl T, Rajewsky N, Rorsman P, Stoffel M: A pancreatic islet-specific microRNA regulates insulin secretion. Nature 2004;432:226-230.

17 Li Y, Xu X, Liang Y, Liu S, Xiao H, Li F, Cheng H, Fu Z: miR-375 enhances palmitate-induced lipoapoptosis in insulin-secreting NIT-1 cells by repressing myotrophin (V1) protein expression. Int J Clin Exp Pathol 2010;3:254-264.

18 Feng B, Chen S, George B, Feng Q Chakrabarti S: miR133a regulates cardiomyocyte hypertrophy in diabetes. Diabetes Metab Res Rev 2010;26:40-49.

19 Wang K, Li P, Dong Y, Cai X, Hou D, Guo J, Yin Y, Zhang Y, Li J, Liang H, Yu B, Chen J, Zen K, Zhang J, Zhang CY, Chen X: A microarray-based approach identifies ADP ribosylation factor-like protein 2 as a target of microRNA-16 J Biol Chem 2011;286:9468-9476.

-20 Liu Q, Fu H, Sun F, Zhang H, Tie Y, Zhu J, Xing R, Sun Z, Zheng X: miR-16 family induces cell cycle arrest by regulating multiple cell cycle genes. Nucleic Acids Res 2008;36:5391-5404.

-21 Lipson KL, Fonseca SG, Ishigaki S, Nguyen LX, Foss E, Bortell R, Rossini AA, Urano F: Regulation of insulin biosynthesis in pancreatic beta cells by an endoplasmic reticulum-resident protein kinase IRE1 Cell Metabolism 2006;4:245-254.

22 Chan CB, Saleh MC, Koshkin V, Wheeler MB: Uncoupling protein 2 and islet function. Diabetes 2004;53 Suppl 1:S136-142.

-23 Chan CB, De Leo D, Joseph JW, McQuaid TS, Ha XF, Xu F, Tsushima RG, Pennefathner PS, Salapatek AMF, Wheeler MB: Increased uncoupling protein-2 levels in beta-cells are associated with impaired glucosestimulated insulin secretion - Mechanism of action. Diabetes 2001;50:1302-1310.

24 Kolfschoten IG, Roggli E, Nesca V, Regazzi R: Role and therapeutic potential of microRNAs in diabetes. Diabetes Obes Metab 2009;11 Suppl 4:118-129.

-25 Del Guerra S, Lupi R, Dotta F, Marselli L, Lencioni C, Santangelo C, Realacci M, Carmellini M, Mosca F, Navalesi R, Marchetti P: Effects of prolonged exposure to pancreatic glucagon on the function, antigenicity and survival of isolated human islets. Diabetes Metab Res Rev 2000;16:281-286.

-26 Eizirik DL, Korbutt GS, Hellerstrom C: Prolonged exposure of human pancreatic islets to high glucose concentrations in vitro impairs the beta-cell function. J Clin Invest 1992;90:1263-1268.

-27 Rossetti L, Giaccari A, Defronzo RA: Glucose Toxicity. Diabetes Care 1990;13:610-630.

28 Weir GC, Leahy JL, Bonner-Weir S: Experimental reduction of B-cell mass: implications for the pathogenesis of diabetes. Diabetes Metab Rev 1986;2:125-161.

29 Chen X, Wang KH, Chen JN, Guo JG, Yin Y, Cai X, Guo X, Wang GQ, Yang R, Zhu LY, Zhang Y, Wang J, Xiang Y, Weng CY, Zen K, Zhang JF, Zhang CY: In vitro Evidence Suggests That miR-133a-mediated Regulation of Uncoupling Protein 2 (UCP2) Is an Indispensable Step in Myogenic Differentiation. Journal of Biological Chemistry 2009;284:5362-5369.

30 Sun LL, Jiang BG, Li WT, Zou JJ, Shi YQ, Liu ZM: MicroRNA-15a positively regulates insulin synthesis by inhibiting uncoupling protein-2 expression. Diabetes Res Clin Pract 2011;91:94-100. 